Int. J. Dev. Biol. 60: 277-288 (2016)

doi: $10.1387 / \mathrm{ijdb} .160158 \mathrm{dl}$

\title{
Use of Xenopus cell-free extracts to study size regulation of subcellular structures
}

\author{
PREDRAG JEVTIĆ\#, ANA MILUNOVIĆ-JEVTIĆ\#, MATTHEW R. DILSAVER, JESSE C. GATLIN* \\ and DANIEL L. LEVY* \\ Department of Molecular Biology, University of Wyoming, Laramie, WY, USA
}

\begin{abstract}
Striking size variations are prominent throughout biology, at the organismal, cellular, and subcellular levels. Important fundamental questions concern organelle size regulation and how organelle size is regulated relative to cell size, also known as scaling. Uncovering mechanisms of organelle size regulation will inform the functional significance of size as well as the implications of misregulated size, for instance in the case of nuclear enlargement in cancer. Xenopus egg and embryo extracts are powerful cell-free systems that have been utilized extensively for mechanistic and functional studies of various organelles and subcellular structures. The open biochemical nature of the extract permits facile manipulation of its composition, and in recent years extract approaches have illuminated mechanisms of organelle size regulation. This review largely focuses on in vitro Xenopus studies that have identified regulators of nuclear and spindle size. We also discuss potential relationships between size scaling of the nucleus and spindle, size regulation of other subcellular structures, and extract experiments that have clarified developmental timing mechanisms. We conclude by offering some future prospects, notably the integration of Xenopus extract with microfluidic technology.
\end{abstract}

KEY WORDS: nuclear size, spindle size, developmental size scaling, midblastula transition, cancer, microfluidics

\section{Introduction}

Size is an important defining feature in biology. Tremendous size variation exists at the species level, as well as at the organ level where organ size tends to correlate with organismal size. Cell size also varies among different eukaryotic species and cell types, and dramatic changes in cell size occur during development, cell division, and differentiation. While our understanding of how cell sizes are regulated is fairly advanced (Fingar et al., 2002, Kozma and Thomas, 2002, Nurse, 1975), less is known about the mechanisms and functional significance of organelle size regulation.

Organelles adopt characteristic architectures, sizes, and shapes. How cells sense and maintain organelle size in order to ensure proper function is an important and largely unexplored question. A related intriguing question is how the sizes and/or numbers of organelles and other subcellular structures are regulated relative to cell size. The sizes of many organelles, including the nucleus and spindle, positively correlate with cell size; large cells tend to have proportionally larger organelles, a phenomenon referred to as scaling (Edens and Levy, 2014b, Jevtic and Levy, 2015, Levy and Heald, 2012, Marshall, 2002, Mitchison et al., 2015, Wilson, 1925). One model to explain organelle scaling invokes limiting pools of cytoplasmic components, where limiting structural proteins or enzymatic activities might restrict organelle size and/or number (Goehring and Hyman, 2012, Good et al., 2013, Hazel et al., 2013). Another possibility is that steady state organelle size is determined by a balance of organelle assembly and disassembly rates, which can also be affected by component limitation (Edens and Levy, 2014a, Loughlin et al., 2011, Marshall et al., 2005, Rafelski et al., 2012, Reber et al., 2013). In a related model, feedback based on organelle size or functional output might impact organelle growth (Marshall, 2012). Changes in organelle sizes and scaling relationships likely affect cell physiology, and

Abbreviations used in this paper: ER, endoplasmic reticulum; INM, inner nuclear membrane; MBT, midblastula transition; MT, microtubule; MTOC, microtubule organizing center; NE, nuclear envelope; NLS, nuclear localization signal; NPC, nuclear pore complex; ONM, outer nuclear membrane; SAF, spindle assembly factor.

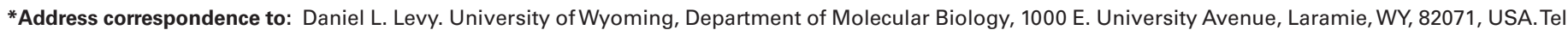

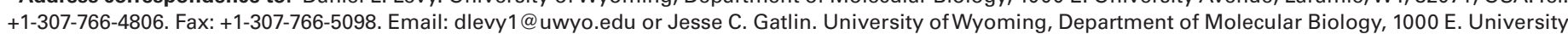
Avenue, Laramie, WY, 82071, USA. Tel: +1-307-766-3498. Fax: +1-307-766-5098. Email: jgatlin@uwyo.edu \#These authors contributed equally to this work.
}

Accepted: 19 May 2016.

ISSN: Online 1696-3547, Print 0214-6282 
aberrations in organelle morphology are associated with certain disease states (Chow et al., 2012, Jevtic and Levy, 2014, Zink et al., 2004).

The Xenopus cell-free extract system has been utilized extensively to study different cellular processes including nuclear assembly and import (Chan and Forbes, 2006), chromosome structure (Maresca and Heald, 2006), and mitotic spindle regulation (Hannak and Heald, 2006). More recently, this in vitro system has provided a useful platform to study mechanisms of organelle size regulation. In this review we largely focus on in vitro Xenopus studies that have revealed regulators of nuclear and spindle size (Fig. 1).

\section{Advantages of using Xenopus cell-free extracts to study organelle size regulation}

Xenopus egg extract is a powerful cell-free system to study the mechanisms and functional significance of organelle size regulation. Detailed methods for the preparation of both $X$. laevis and $X$. tropicalis egg extracts have been described (Brown et al., 2007, Desai et al., 1999, Edens and Levy, 2014b, Hannak and Heald, 2006, Murray, 1991). Female Xenopus frogs are primed and induced to lay eggs with gonadotropin hormone injections. The egg jelly coats are removed, and washed eggs are subjected to a crushing centrifugation step, followed by collection of the nearly undiluted cytoplasm that contains the membranes and cytoplasmic proteins necessary to assemble organelles in vitro. Egg extracts do not contain the egg chromosomes, so addition of an exogenous chromatin source, usually demembranated Xenopus sperm chromatin, is necessary to initiate nuclear and spindle assembly. Laid amphibian eggs are arrested in metaphase of meiosis II, and simple manipulations allow for cycling of egg extracts between interphase and mitosis. Due to the open biochemical nature of the extract, recombinant proteins can be added or endogenous proteins can be immunodepleted or inhibited with neutralizing antibodies or small molecules. Addition of fluorescently labeled proteins or dyes allows for visualization of organelles and subcellular structures, performance of functional assays, and live time-lapse imaging of dynamic processes.

Similar to egg extracts, embryo extracts can be generated from both $X$. laevis and $X$. tropicalis embryos at different developmental stages. During early Xenopus embryogenesis, cell divisions are rapid without changes in the size of the embryo itself, and as such it provides a powerful cellular scaling system. In $X$. laevis the $\sim 1.2 \mathrm{~mm}$ diameter fertilized egg undergoes twelve rapid, synchronous cell cycles (each approximately 25 to 30 minutes), to produce about four thousand 40-190 $\mu \mathrm{m}$ cells (average 100 $\mu \mathrm{m}$ diameter) at the midblastula transition (MBT), also referred to as stage 8.5 (Jevtic and Levy, 2015, Nieuwkoop and Faber, 1967). As the embryo proceeds through gastrulation (stages 10.5-12), further reductions in cell size occur, reaching 12-30 $\mu \mathrm{m}$ in the tadpole (average $20 \mu \mathrm{m}$ diameter, our unpublished measurements). Both nuclear size and spindle size decrease throughout Xenopus early embryonic development, providing a robust system to investigate organelle scaling (Jevtic and Levy, 2015, Levy and Heald, 2010, Wuhr et al., 2008).

The preparation and use of embryo extracts from different developmental stages are nearly the same as for egg extract (Edens and Levy, 2014b, Edens and Levy, 2016, Jevtic et al., 2015).
One notable difference is that endogenous organelles, such as nuclei and spindles, can be observed in their native cytoplasm, as it is not necessary to add an exogenous chromatin source to embryo extracts. Methods for manipulating extract composition and visualizing structures and activities are the same. Changes in scaling factor abundance and localization during development can be determined by immunoblotting different stage embryo extracts and performing immunofluorescence on embryos. The analysis and interpretation of embryo extract experiments is facilitated by recent transcriptomic and proteomic studies in Xenopus (Collart et al., 2014, Peshkin et al., 2015, Wuhr et al., 2014, Yanai et al., 2011). Thus, both egg and embryo extracts represent robust in vitro systems to elucidate mechanisms of organelle size regulation.

\section{Nuclear structure and significance of nuclear size regulation}

Many structural components of the nucleus contribute to the proper regulation of nuclear morphology. The nuclear envelope (NE) consists of an outer nuclear membrane (ONM) and inner nuclear membrane (INM), with the ONM being continuous with the endoplasmic reticulum (ER). Inserted at sites of ONM-INM fusion are nuclear pore complexes (NPCs) that mediate nucleocytoplasmic transport (Fig. 1). The classical nuclear import pathway is mediated by importin $\alpha$, a nuclear import receptor that binds to cargos containing a nuclear localization signal (NLS), and importin $\beta$, that mediates interactions with the NPC. Inside the nucleus, Ran-GTP binds to importin $\beta$ causing release of importin $\alpha$ and NLS cargos. Importin $\beta$ bound to Ran-GTP is exported to the cytoplasm where nucleotide hydrolysis converts Ran-GTP to Ran-GDP. Nuclear transport factor 2 (NTF2) binds to both Ran-GDP and FxFG repeat-containing nucleoporins, acting as a dedicated nuclear import factor for Ran-GDP, which is converted to Ran-GTP in the nucleus by its guanine nucleotide exchange factor, chromatin-bound RCC1 (Fig. 1) (Madrid and Weis, 2006, Stewart, 2007). The INM is lined on its nucleoplasmic face by the nuclear lamina and chromatin. The nuclear lamina is a meshwork of intermediate filaments that provides mechanical strength to the nucleus and contributes to chromatin organization, transcriptional regulation, and DNA metabolism (Gruenbaum et al., 2005, Walters et al., 2012, Worman and Courvalin, 2005). The main structural components of the nuclear lamina are the nuclear lamin proteins, which in somatic vertebrate cells include lamin B1, B2, and A/C (Fig. 1) (Misteli and Spector, 2011, Parnaik et al., 2011).

Changes in nuclear size are linked to normal physiological events such as development, cell division, and differentiation (Edens et al., 2013, Jevtic et al., 2014, Levy and Heald, 2012, Vukovic etal., 2016a), while aberrations in nuclear size and shape are associated with aging (Prokocimer et al., 2009) and cancer (Chow et al., 2012, Jevtic and Levy, 2014). Enlarged nuclear size is a morphometric feature commonly used by cytopathologists to diagnose, stage, and prognose many different cancers (Zink et al., 2004). The functional link between malignancy and altered nuclear size is not clear, and notably, cancer-associated changes in nuclear size often do not correlate with increased DNA content (Jevtic and Levy, 2014). Do changes in chromatin organization and gene expression during tumorigenesis result from or cause increased nuclear size? Using the Xenopus system to elucidate mechanisms of nuclear size regulation will provide insight into 
the functional significance of nuclear size and improve our understanding of the link between altered nuclear size and disease states such as cancer.

\section{Mechanisms of interspecies nuclear scaling}

$X$. laevis frogs, cells, eggs, and nuclei are larger than those of $X$. tropicalis, offering a physiological scenario in which to investigate mechanisms of nuclear size control. Interspecies nuclear scaling was recapitulated using egg extracts from these two related Xenopus species. Nuclei assembled with $X$. laevis sperm chromatin in $X$. laevis egg cytoplasm expanded more rapidly and were larger than in $X$. tropicalis cytoplasm. Mixing the two different egg extracts produced nuclei of intermediate size, suggesting that titratable cytoplasmic factors regulate nuclear size in this system. Nuclei assembled with $X$. tropicalis sperm, having around half the DNA content of $X$. laevis sperm, were minimally smaller, showing that cytoplasm has a greater effect on nuclear size than bulk DNA content. Rates of nuclear import were found to differ between the two extracts, with faster import into $X$. laevis nuclei than $X$. tropicalis nuclei. The levels of two nuclear import factors were found to be different between the two extracts. $X$. laevis extract has a higher concentration of importin $\alpha$, while $X$. tropicalis extract has a greater concentration of NTF2 (Fig. 2A). Altering the levels of both import factors was nearly sufficient to account for nuclear import and nuclear size differences between these two species (Levy and Heald, 2010). Both factors modulate lamin B3 (LB3) import, the major egg lamin required for NE growth (Jenkins et al., 1993, Newport et al., 1990), with importin $\alpha$ increasing overall import rates and NTF2 reducing import based on cargo size (Levy and Heald, 2010). These experiments demonstrated a role for nuclear import and nuclear structural components as physiological regulators of nuclear size in Xenopus.

As a follow-up to these studies, we tested how NTF2 concentrations and mutants affect nuclear size in $X$. laevis egg and embryo extracts. Using a mutant version of NTF2 that is defective for Ran binding, we showed that the ability of NTF2 to inhibit nuclear growth and import of large cargo molecules, such as lamins, depends on its binding to Ran. An NTF2 mutant with reduced affinity for the NPC was also defective in limiting nuclear growth, thus implicating binding of NTF2 to both Ran and the NPC in nuclear size regulation. Ectopic NTF2 expression in Xenopus early embryos also

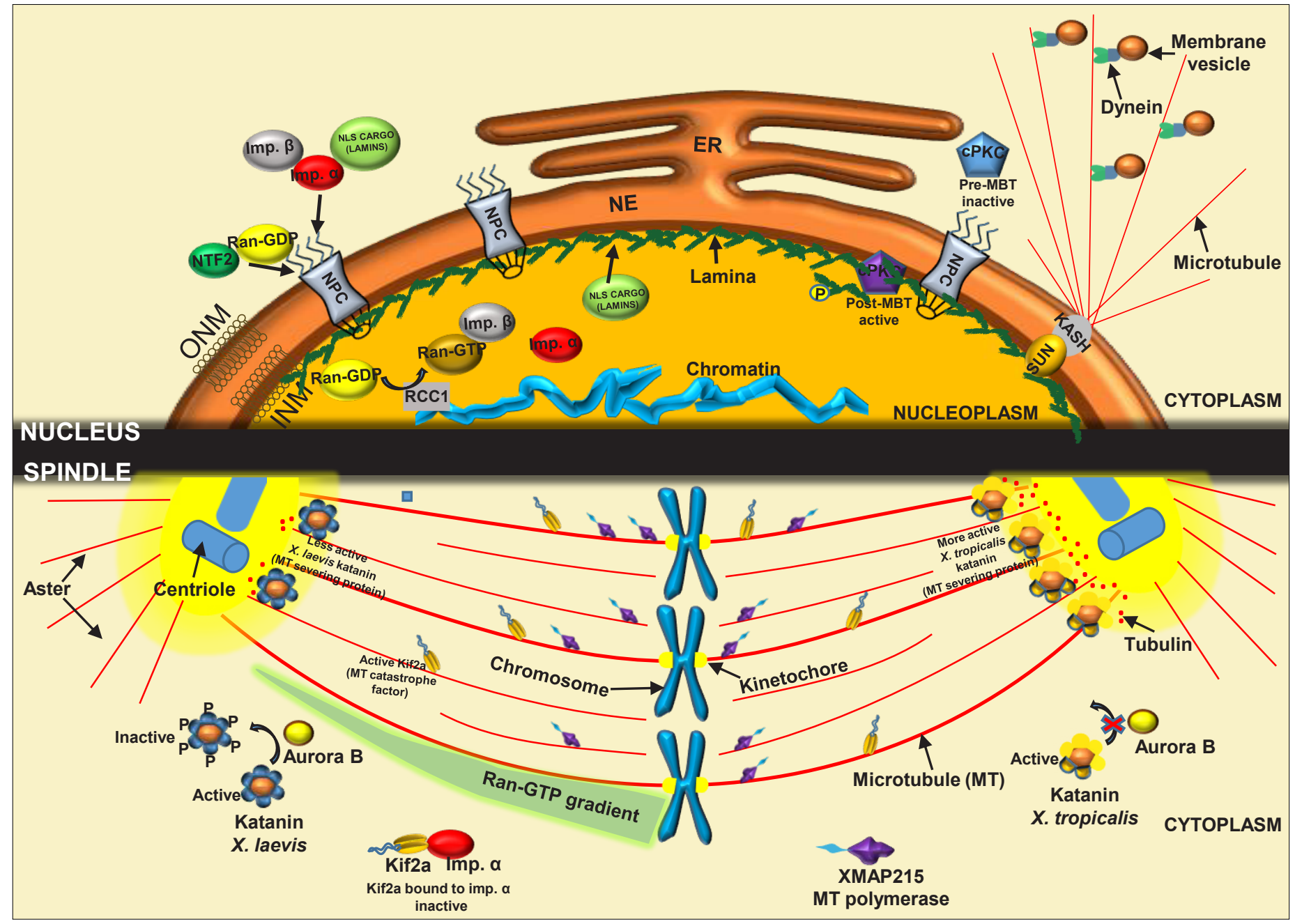

Fig. 1. Summary of some of the mechanisms that contribute to the regulation of nuclear and spindle size that were elucidated using Xenopus extracts. 
led to altered nuclear size. We propose that NTF2 bound to Ran reduces the effective diameter of the NPC pore, inhibiting import of large cargos and nuclear expansion. In support of this model, transmission electron microscopy showed that egg extract nuclei supplemented with wild-type NTF2 exhibited a $20-30 \%$ reduction in average NPC diameter (Fig. 2B). In contrast, the Ran binding mutant, though still effectively recruited to the NPC, did not alter NPC size (Vukovic et al., 2016b). This new mechanistic information about how NTF2 affects nuclear size will facilitate future studies into the functional significance of nuclear size during development, differentiation, and carcinogenesis.

\section{Mechanisms of developmental nuclear scaling}

During $X$. laevis early embryogenesis, nuclear volume decreases $\sim 3$-fold during the cleavage cell divisions and up to the MBT, and this reduction in nuclear size correlates with reductions in cytoplasmic importin $\alpha$ levels and bulk import (Levy and Heald, 2010, Wilbur and Heald, 2013). From the MBT through gastrulation, another 3-fold reduction in nuclear volume occurs. To test what contributes to this post-MBT nuclear size scaling, we developed an in vitro nuclear re-sizing assay using Xenopus embryo extracts. When large egg extract nuclei were incubated in gastrula stage embryonic cytoplasm, the nuclei became smaller. Further experiments showed that this nuclear shrinking activity present in late stage embryonic cytoplasm was dependent on conventional protein kinase $\mathrm{C}(\mathrm{cPKC})$. Both cPKC activity and nuclear localization were observed to increase in post-MBT embryos, correlating with reduced nuclear size and decreased nuclear localization of lamins (Fig. 1, Fig. 2C). Furthermore, manipulating cPKC activity in vivo was sufficient to alter interphase nuclear size in post-MBT embryos. From these studies, we propose that steady-state nuclear size is established through a balance of nuclear import-mediated growth and cPKC-dependent nuclear shrinking (Edens and Levy, 2014a). Future studies will address if nuclear lamins are directly phosphorylated by cPKC to regulate interphase lamina dynamics and nuclear size. How these developmental changes in nuclear size and dynamics affect nuclear mechanics is a question for future study.

We further investigated how nuclear lamins affect nuclear size in $X$. laevis egg and embryo extracts. During early $X$. laevis development, the expression of different lamin isoforms changes, as does the total lamin concentration (Benavente et al., 1985, Jevtic et al., 2015, Stick and Hausen, 1985). To test how the level and type of lamin expression influence nuclear size, we titrated recombinant lamin proteins into egg and embryo extracts. We found that nuclear growth and size were sensitive to the levels of nuclear lamins, with low and high concentrations increasing and decreasing nuclear size, respectively (Fig. 2D). Interestingly, each type of lamin we tested (lamin B1, B2, B3, A) similarly affected nuclear size, whether added alone or in combination. These data suggest that total lamin concentration, and not lamin type, is more critical in determining nuclear size (Jevtic et al., 2015). How might relatively low levels of ectopic lamins increase nuclear size? Nuclear import capacity in $X$. laevis egg extract is extremely high, so even relatively low amounts of added lamins might be expected to alter nuclear size. Why might higher lamin levels reduce nuclear size? It is possible that when lamins are imported into the nucleus too rapidly, due to fast import kinetics, they are unable to properly incorporate into the lamina, leading to observed intranuclear lamin aggregates. These aggregates may have a dominant-negative effect, extracting endogenous lamins from the nuclear lamina and leading to a reduction in nuclear size. In support of this idea, high concentrations of a LB3 CAAX box mutant, defective for farnesylation and targeting to the lamina, still formed intranuclear aggregates and decreased nuclear size, while
A

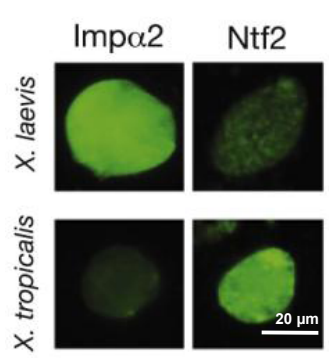

B

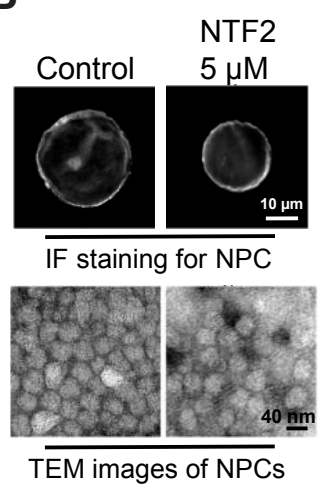

C

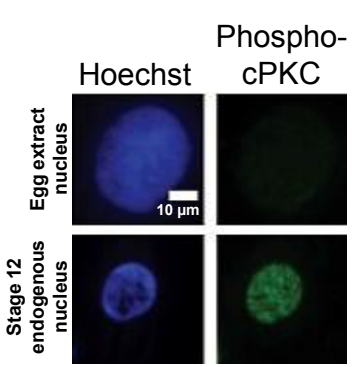

D

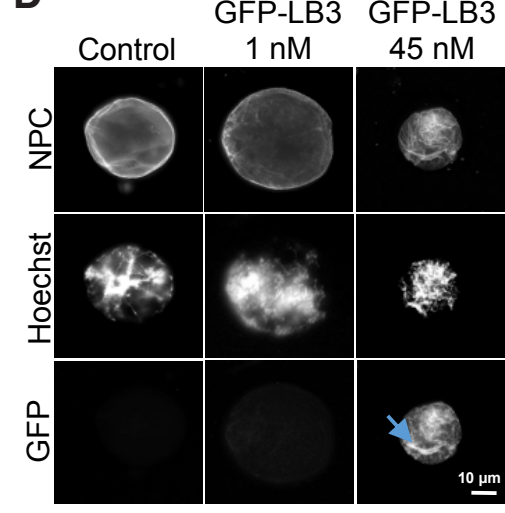

E

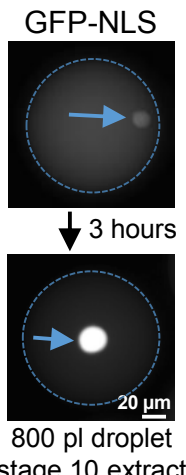

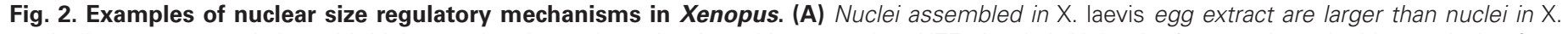

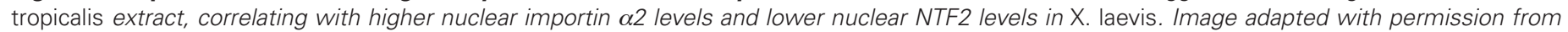

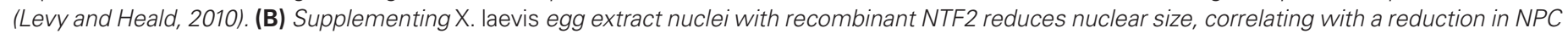

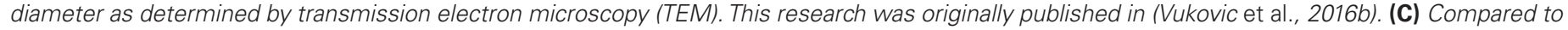

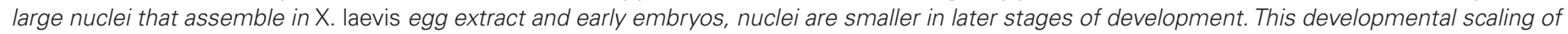

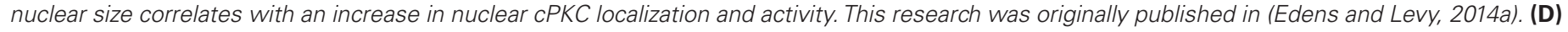

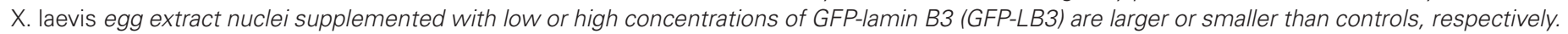

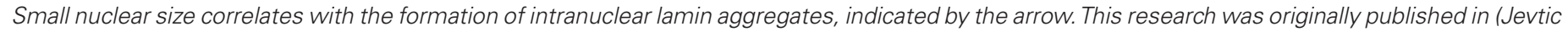

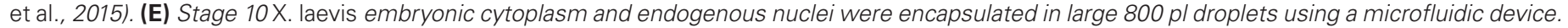

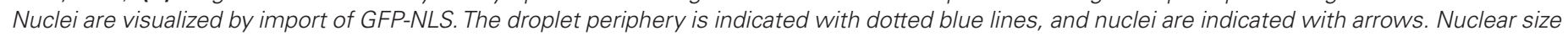
expands over the course of $\sim 3$ hours at room temperature (our observation). 
high concentrations of a LB3 point mutant defective for lamina assembly did not (Jevtic et al., 2015).

\section{Other factors that influence nuclear size}

A number of additional factors that impact nuclear size have been studied using Xenopus extracts. Depletion of the nucleoporin Nup188 from Xenopus egg extract caused accelerated import of INM proteins with a concomitant increase in nuclear size (Theerthagiri et al., 2010). Addition of a dominant-negative fragment of POM121, an integral membrane nucleoporin, to egg extract inhibited NE growth (Shaulov et al., 2011). TPX2, an important regulator of spindle assembly and size (Helmke and Heald, 2014), localizes to the nucleus in interphase by binding lamina-associated polypeptide 2 (LAP2). Depletion of TPX2 from Xenopus egg extract led to the formation of small nuclei (O'Brien and Wiese, 2006), and addition of the chromatin- or lamin-binding domain of LAP2 to Xenopus egg extract inhibited nuclear growth (Gant et al., 1999). These data suggest that TPX2 and its interaction with LAP2 are required for normal nuclear size regulation, and that lamina-chromatin interactions contribute to proper nuclear size determination.

Extranuclear structures also contribute to the regulation of nuclear size and morphology. During late mitosis, clearance of microtubules (MTs) from the recently segregated chromosomes is important for normal nuclear assembly and morphology in the subsequent interphase. One protein responsible for removing these MTs is the developmental pluripotency-associated 2 (Dppa2) protein that binds to chromatin and inhibits MT polymerization. Depletion of Dppa2 from Xenopusegg extract led to inappropriate accumulation of MTs around the post-mitotic chromatin, causing the formation of small misshapen nuclei. Strikingly, treatment with MT depolymerizing drugs rescued this nuclear morphology defect (Xue et al., 2013). Clearance of membrane from mitotic chromosomes is also important for normal nuclear morphology. A biochemical screen for MT-membrane linkers using Xenopus egg extract identified REEP4, and depletion of the MT-binding ER proteins REEP3/4 in HeLa cells resulted in inappropriate membrane accumulation around metaphase chromosomes with concomitant NE defects during interphase (Schlaitz et al., 2013).

Also important in nuclear size regulation is the $E R$, an interconnected membrane network consisting of highly curved ER tubules and flat cisternal sheets. The NE is continuous with the ER, so alterations in ER composition can affect nuclear morphology. Experiments using fractionated Xenopus egg extract showed that NE assembly involves targeting of ER tubules to chromatin, followed by membrane spreading around the chromatin. Disruption of ER membranes using shear mechanical stress inhibited nuclear growth, and reformation of an ER network allowed for NE re-growth (Anderson and Hetzer, 2007). Proteins in the reticulon (Rtn) and REEP families shape ER tubules by inserting hydrophobic wedges into the lipid bilayer to induce membrane curvature (Voeltz et al., 2006, West et al., 2011). Nuclei failed to form in egg extract treated with an Rtn4a neutralizing antibody, and disruption of ER network re-formation using an inhibitory antibody against Ufd1 (an adapter protein of the AAA-ATPase p97 required for ER network maintenance) slowed the growth of pre-assembled nuclei (Anderson and Hetzer, 2007). These results demonstrate that a tubular ER is necessary for both nuclear assembly and expan- sion. Rtn4 overexpression in early Xenopus embryos also altered nuclear size (Jevtic and Levy, 2015). Rtns are thought to impact nuclear size through a tug-of-war competition between nuclear and ER membrane availability, such that an increase in ER tubulation leads to a reduction in NE membrane and nuclear size (Anderson and Hetzer, 2008). Important questions for future research are how cytoplasmic volume affects ER size and morphology, and how such ER scaling might impact the regulation of nuclear size.

\section{Contributions of nuclear volume, cytoplasmic volume, and DNA amount to MBT timing}

The MBT is the first major developmental transition during early $X$. laevis embryogenesis when abrupt zygotic transcription begins and cell cycles elongate. Elegant experiments in which cytoplasmic volume or DNA amount were varied in embryos supported the idea that the DNA-to-cytoplasmic volume ratio regulates MBT onset. By this model, maternally derived DNA-binding MBT inhibitors present in a fixed cytoplasmic volume are titrated against exponentially increasing genomic DNA amounts during the cleavage stages of early development. Once a critical DNA amount is reached that exceeds the binding capacity of available inhibitors, the MBT is induced (Clute and Masui, 1995, Newport and Kirschner, 1982a, Newport and Kirschner, 1982b). Recently, a number of potential limiting components have been identified as candidate regulators of MBT onset. The levels of four DNA replication initiation factors (Cut5, RecQ4, Treslin, and Drf1) were fully titrated from egg extract cytoplasm at a DNA-to-cytoplasm ratio characteristic of the MBT. Overexpression of all four DNA replication factors in Xenopus embryos increased DNA replication rates by increasing origin firing and delayed the MBT as evidenced by a delay in the onset of zygotic gene expression and greater numbers of rapid synchronous cell divisions prior to cell cycle lengthening (Collart et al., 2013). Another Xenopus extract study also found that DNA replication rates and origin firing are reduced at the high DNAto-cytoplasm ratios found at the MBT. However, in this study, the limiting components were identified as the protein phosphatase PP2A and its regulatory subunit B55 $\alpha$ (Murphy and Michael, 2013).

$X$. laevis egg extract has also been used to identify factors that directly regulate the onset of zygotic gene expression at the MBT. By adding increasing amounts of sperm chromatin to a fixed volume of egg extract, a critical DNA-to-cytoplasm ratio, similar to that found in the embryo at the MBT, was capable of triggering new transcription. Removal of DNA-binding proteins from extract using DNA-coated magnetic beads generated an extract capable of activating transcription at much lower concentrations of sperm chromatin, demonstrating that the transcriptional inhibitor is a DNA-binding protein. Subsequent biochemical fractionation identified histones $\mathrm{H} 3$ and $\mathrm{H} 4$ as the putative MBT inhibitors. Supplementing egg extract with recombinant $\mathrm{H} 3$ and $\mathrm{H} 4$ increased the DNA threshold required for activation of transcription in a dosage-dependent manner, while histone depletion allowed for transcriptional activation with lower DNA amounts. In addition, manipulating histone levels in vivo affected the timing of MBTassociated changes in cell cycle lengths (Amodeo et al., 2015).

The DNA-to-cytoplasm ratio may not be the only parameter that determines MBT timing. During early $X$. laevis embryogenesis, cell size scales smaller at a much faster rate than nuclear size. From stage 4 to stage 8.5 , average nuclear volume reduces 
3-fold, while cytoplasmic volume shows a much more dramatic $\sim 70$-fold reduction. As a consequence of this difference in scaling rates, the nuclear-to-cytoplasmic (N/C) volume ratio increases rapidly during early development, reaching a maximum at the MBT (Jevtic and Levy, 2015). To test how nuclear size and the $\mathrm{N} / \mathrm{C}$ volume ratio impact the onset of the MBT, we altered nuclear size in $X$. laevis embryos by ectopically expressing nuclear scaling factors known to affect nuclear size: importins, lamins, and reticulons. We found that increasing nuclear size and the N/C volume ratio led to premature onset of zygotic gene transcription and cell cycle lengthening. Conversely, decreasing nuclear size in early embryos delayed activation of zygotic transcription and cell cycle lengthening (Jevtic and Levy, 2015). These studies raise a number of questions about the regulation of MBT timing. What are the relative contributions of nuclear size and DNA amount to MBT timing? Do changes in nuclear volume alter the intranuclear concentrations of limiting, maternally derived DNA binding factors? If so, the MBT might be regulated not only by the total amount of these maternally deposited limiting components but by their nuclear concentrations, as determined by changes in total nuclear volume during early embryogenesis. Do changes in nuclear size affect the MBT by altering chromatin compaction and organization? How might changes in NE surface area affect import capacity and the import of limiting DNA binding components that in turn regulate MBT timing? Future experiments using Xenopus egg and embryo extracts promise to provide answers.

\section{Metaphase spindle structure and significance of spindle size regulation}

Xenopus is an incredibly powerful model system for studying size regulation of the interphase nucleus, and it has been just as useful for elucidating mechanisms that control the size of the mitotic spindle. Like the nucleus, the size of the mitotic spindle scales with cell size during development (Courtois et al., 2012, Good et al., 2013, Wuhr et al., 2008). The spindle apparatus plays a major role in cell division, ensuring proper chromosome segregation. While the length of the spindle seems to be important for accurate segregation of chromosomes (Schubert and Oud, 1997), it is unknown whether there is a causal link between altered spindle size and disease. The spindle is composed of dynamic microtubule (MT) arrays organized into a steady-state structure with two focused poles (Fig. 1).Approximately 150 well-characterized spindle assembly proteins regulate MT nucleation, polymerization dynamics, cross-linking, sliding, and focusing, regulated by kinases, phosphatases, and checkpoints (Sauer et al., 2005). Spindle length, defined as the distance from one spindle pole to another, is tightly regulated during metaphase so that the distance between segregated anaphase chromosomes is sufficient to ensure each daughter cell receives a full complement of chromosomes [for review see (Goshima and Scholey, 2010)]. Since the number of spindle poles often dictates the number of daughter cells, accurate segregation of the duplicated genome and viability of daughter cells require a bipolar structure.
A
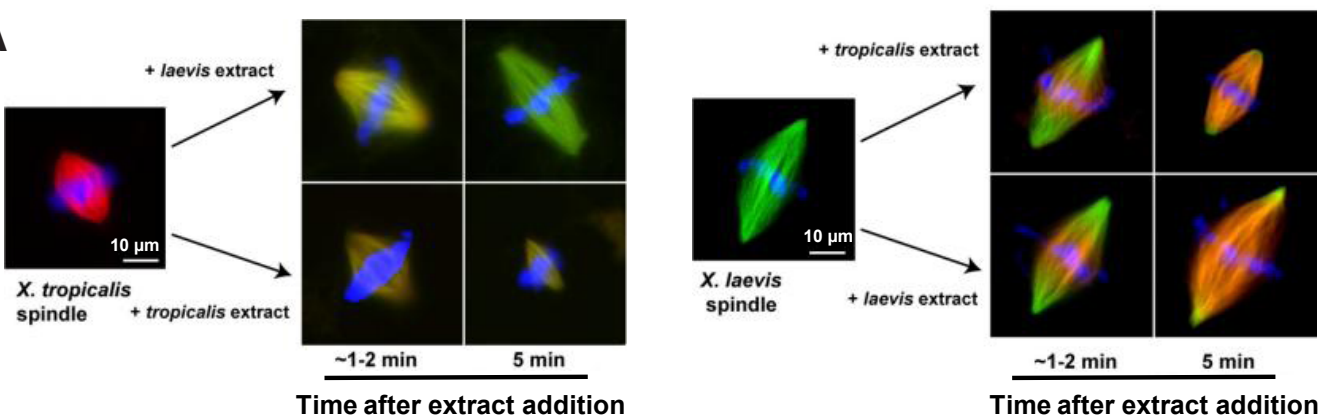

B
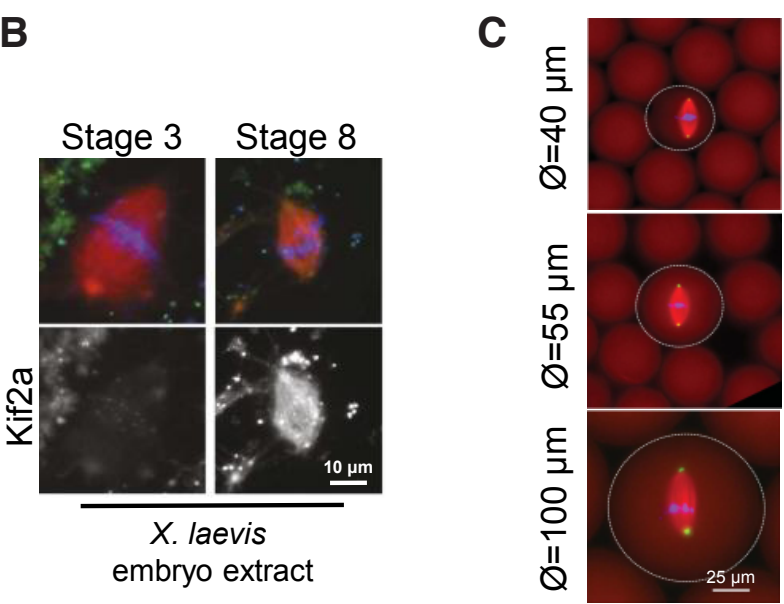

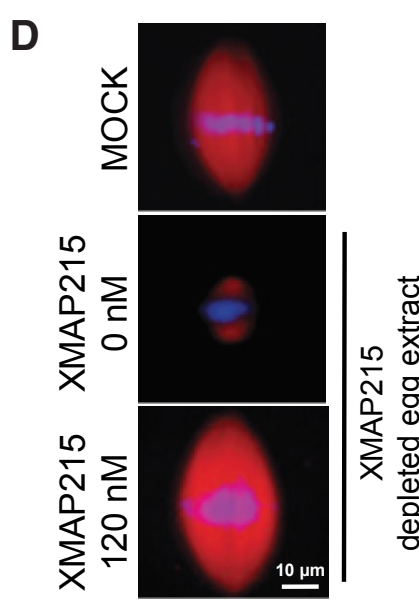

Fig. 3. Examples of spindle size regulatory mechanisms in Xenopus. (A) Spindles assembled in X. tropicalis egg extract are smaller than spindles assembled in $\mathrm{X}$. laevis egg extract. Spindle length regulation is dynamic, as adding $\mathrm{X}$. laevis egg extract to a $X$. tropicalis spindle leads to spindle growth, while addition of $\mathrm{X}$. tropicalis egg extract induces shrinking of a X. laevis spindle. Image adapted with permission from (Brown et al., 2007). (B) Spindles assembled in early stage $\mathrm{X}$. laevis embryo extract are larger than spindles assembled in later stage embryo extract. This developmental reduction in spindle length correlates with increased spindle localization of the MT-depolymerizer kif2a. Image adapted from (Wilbur and Heald, 2013) under a Creative Commons License (http://creativecommons. org/licenses/by/4.0/). (C) X. laevis egg extract was encapsulated in droplets of varying size using microfluidic devices. The length of the assembled spindle correlates with the volume of the droplet. Image adapted with permission from (Hazel et al., 2013). (D) Spindles assembled in X. laevis egg extract depleted of the MT polymerase XMAP215 are small, and titration of recombinant XMAP215 into this extract results in a graded increase in spindle length. Image adapted with permission from (Reber et al., 2013). 
This is particularly relevant in cancer cells containing supernumerary centrosomes (more than two) (Ganem et al., 2009, Milunovic-Jevtic et al., 2016). In the next few sections of this review, we will focus on how Xenopus egg and embryo extracts have provided insights into the mechanisms that control metaphase spindle size and shape.

\section{Mechanisms of interspecies spindle scaling}

As in the case of the nucleus, studies comparing $X$. laevis and $X$. tropicalis egg extracts have illuminated mechanisms of spindle size control. X. tropicalis spindles are shorter than $X$. laevis spindles (Brown et al., 2007), correlating with higher MT severing activity in $X$. tropicalis egg extract (Fig. 3A). Specifically, X. tropicalis katanin, a MT severing enzyme, was shown to be more active than $X$. laevis katanin due to the absence of an inhibitory phosphorylation site in the $X$. tropicalis katanin p60 catalytic subunit (Fig. 1). Katanin p60 depletion from $X$. tropicalis extract resulted in longer spindles that could be rescued by addition of wild-type $X$. tropicalis $p 60$ or $X$. laevis p60 with its inhibitory phosphorylation site mutated to alanine. These results demonstrate how species-dependent phosphorylation of a single protein can affect spindle size (Loughlin et al., 2011). TPX2 also contributes to the interspecies difference in spindle size, through its interaction with the kinesin- 5 motor protein Eg5. Threefold higher TPX2 levels are found in $X$. tropicalis egg extract, and addition of recombinant TPX2 to $X$. laevis egg extract was sufficient to reduce spindle length (Helmke and Heald, 2014).

While cytoplasmic composition is an important determinant of spindle length, DNA amount only slightly affects spindle length. Egg extract spindles assembled with $X$. tropicalis sperm were $\sim 10 \%$ shorter than those assembled with $X$. laevis sperm, likely due to $X$. tropicalis having approximately half the genome size of $X$. laevis (Brown et al., 2007). These findings are consistent with the observations that spindles in diploid versus haploid embryos are on average only $10 \%$ longer (Wuhr et al., 2008), and the same modest difference in length was also found in comparing spindles before and after pairwise fusions in X. laevis extracts (Gatlin et al., 2009). A small increase in spindle length was also seen when the amount of chromatin was modulated on the surfaces of patterned, chromatin-coated beads (Dinarina etal., 2009). In these experiments, a $\sim 5 x$ increase in chromatin mass on the bead surface resulted in only a $\sim 10 \%$ increase in spindle length. Interestingly, changing the spatial arrangement of chromatin seems to have more marked effects on spindle shape than on spindle size (Dinarina et al., 2009, Gaetz et al., 2006).

\section{Mechanisms of developmental spindle scaling}

Developmental spindle scaling is another unexplained biological phenomenon. In early stages of $X$. laevis embryonic development, spindle length is $\sim 60 \mu \mathrm{m}$ and is maintained through several divisions at this upper limit irrespective of cell size (Wuhr et al., 2008). By the seventh cleavage, a scaling relationship between cell and spindle size begins to emerge, in which smaller cells exhibit shorter spindles. This scaling relationship is evident when comparing differing size cells both between and within developmental stages (Wuhr et al., 2008). Though it has become clear that changes in cytoplasmic volume are sufficient to drive spindle length scaling (Good et al., 2013, Hazel et al., 2013), there is evidence that changes in developmental cues are also involved. In studies utilizing $X$. laevis embryo extracts, the reduction in spindle size between stage 3 and stage 8 was shown to correlate with an increase in the activity of the MT-destabilizing kinesin-13 kif2a (Wilbur and Heald, 2013). While the total level of kif2a was similar in stage 3 and stage 8 embryos, in stage 3 extracts kif2a was bound to importin $\alpha$ and inhibited. At stage 8 , sequestration of importin $\alpha$ into a membrane pool resulted in deinhibition of kif2a, leading to increased MT catastrophe frequency, less stable MTs, and smaller spindles (Wilbur and Heald, 2013). These data support the idea that changes in developmental context can contribute to altered spindle size (Fig. 1, Fig. 3B).

While studies in bulk embryo extracts have revealed developmental regulators of spindle size, these types of experiments fail to capture information about the potential contribution of cell size and cytoplasmic volume to spindle size. Interestingly, spindle size can vary within the same developmental stage where cell sizes can differ dramatically. For example, in stage 8 embryos spindles are $\sim 20 \mu \mathrm{m}$ long in small animal pole cells, while $\sim 50 \mu \mathrm{m}$ long spindles are found in large cells of the vegetal pole (Wilbur and Heald, 2013). To test how cell size might affect spindle size, studies were conducted combining Xenopus cell-free extracts with microfluidic technology, discussed in greater detail later in this review. Using microfluidic devices to confine spindle assembly to egg extract droplets of defined sizes, it was demonstrated that spindle size correlated with droplet size (Fig. 3C), thus supporting the idea that spindle size is determined in part by cytoplasmic volume (Good et al., 2013, Hazel et al., 2013).

What spindle assembly component(s) might become limiting for spindle size in small cytoplasmic volumes? Tubulin itself is one possibility, given that it is the major building block of the spindle (Good et al., 2013). Other potential limiting components include the flux-generating kinesin Eg5 (Burbank et al., 2007, Miyamoto et al., 2004), which maintains spindle length in part by producing an outward force on spindle poles (Dumont and Mitchison, 2009), and the MT polymerase XMAP215, which was recently found to regulate spindle length in a concentration-dependent manner in $X$. laevis egg extracts (Reber et al., 2013). XMAP215 is particularly intriguing because, at least in $X$. laevis, it is present at relatively low concentrations $(-120 \mathrm{nM})$ even before partitioning into the spindle, and small changes in protein concentration affect spindle size (Reber et al., 2013). XMAP215 promotes MT growth in X. laevis egg extract (Gard and Kirschner, 1987, Tournebize et al., 2000) and is expressed in Xenopus embryos from oogenesis through tadpole stages with proposed roles in regulating MT dynamics during rapid cell divisions as well as in development of the nervous system (Becker and Gard, 2000). By varying the XMAP215 concentration in $X$. laevis egg extracts, it was demonstrated that spindle size scaled with XMAP215 levels (Fig. 3D), and mutating XMAP215 to alter its polymerase activity also resulted in concomitant changes in spindle length (Reber et al., 2013). XMAP215 activity is thought to regulate spindle size by promoting increased MT growth velocity, thereby affecting total MT mass within the spindle. This mechanism of action is consistent with XMAP215 being a potential effector of spindle scaling, but whether it becomes limiting during spindle assembly in small cytoplasmic volumes remains unknown. Ultimately, in order to determine which candidate proteins might be bona fide scaling factors, it will be important to measure how modulating their levels affects the cell-spindle size scaling curve. It will also be important to measure how each partitions between the cytoplasm and spindle in limiting cytoplasmic volumes. 
Given that spindle size scales during development, a related question is whether there is scaling of mitotic chromosome size. Interestingly, no interspecies scaling of mitotic chromosomes was observed comparing $X$. laevis and $X$. tropicalis egg extracts, in which assembled chromosomes exhibited similar average lengths and widths. On the other hand, during $X$. laevis development mitotic chromosome length was observed to decrease between stages 7 to 11 while width remained unchanged. From stage 11 to 20 , both chromosome length and width decreased (Kieserman and Heald, 2011). Concomitant scaling of mitotic chromosome and spindle lengths may help to ensure complete chromosome segregation in small cells. Interestingly, mitotic chromosome scaling does not appear to correlate with nuclear scaling during early stages of Xenopus development. However, it was noted that blocking expansion of nuclei assembled in egg extract resulted in smaller mitotic chromosomes, suggesting nuclear volume can influence chromosome size (Hara et al., 2013), consistent with chromosomal size scaling observed in C. elegans (Ladouceur et al., 2015) and defective chromosome segregation in fission yeast with small nuclei (Takemoto et al., 2016).

\section{Regulation of spindle shape}

Another fundamental question is how the dynamic assembly of spindle MTs is able to achieve a bipolar spindle-like shape. While centrosomes are clearly important, during female meiosis in vertebrates, bipolar spindles assemble around chromatin in a centrosome-independent manner. In meiotic egg extracts, this process is often spatially localized around exogenously added sperm nuclei or chromatin-coated microbeads (Heald et al., 1996). MTs nucleated around chromatin beads are able to self-organize into a bipolar spindle-like structure through the combined action of multiple different MT motor proteins (Walczak et al., 1998). A robust spindle pole focusing mechanism was demonstrated in experiments where forced fusion of two pre-assembled spindles resulted in a single bipolar structure (Gatlin et al., 2009). This de novo pole focusing also occurs in mitotic somatic cells that have been stripped of centrosomes using targeted laser ablation, indicating centrosomes are not required to ensure spindle bipolarity (Khodjakov et al., 2000).

Proper bipolar spindle shape is essential for cell division in normal and cancerous cells. Many cancers contain cells with supernumerary centrosomes (Chan, 2011), which pose a unique challenge to the cell division machinery. In order for these cells to divide and produce viable progeny, centrosomes must be clustered during prometaphase to avoid a multipolar anaphase, massive aneuploidy, and daughter cell death (Ganem et al., 2009). Multipolar divisions are very rare because cancer cells will cluster multiple centrosomes into only two poles, overcoming multipolar chromosome segregation at anaphase (Godinho et al., 2009). Cell-free Xenopus egg extract, particularly in combination with microfluidic-based encapsulation strategies, represents a promising system to study the mechanism of centrosome clustering and the transition from multipolar to bipolar spindles, as the number of microtubule organizing centers (MTOCs), either in the form of isolated centrosomes or artificial MTOCs (Tsai and Zheng, 2005), in a given volume can be easily modulated.

\section{Relationship between size scaling of the spindle and nucleus}

Do common mechanisms regulate size scaling of the spindle and nucleus? Generally, the sizes of both the nucleus and spindle scale with cell size, in other words smaller cells tend to have both a smaller nucleus and spindle. For example, smaller spindles $(\sim 10 \mu \mathrm{m}$ pole to pole distance) and nuclei ( $10 \mu \mathrm{m}$ in diameter) are present in HeLa cells compared to spindles $(\sim 40 \mu \mathrm{m})$ and nuclei $(\sim 20 \mu \mathrm{m})$ assembled in $X$. laevis egg extract. One activity that is important for both spindle and nuclear function is the small GTPase Ran. While Ran is a key regulator of nucleocytoplasmic transport in interphase, it also facilitates spindle assembly in mitosis when RanGTP binds importin family nuclear transporters and releases spindle assembly factors (SAFs) essential for MT nucleation and assembly of a bipolar spindle. Chromatin-bound guanine nucleotide exchange factor RCC1 converts RanGDP to RanGTP generating an enrichment of RanGTP and activated SAFs around the chromatin (Fig. 1) (Caudron et al., 2005, Kalab et al., 2002). Since RanGTP and associated SAF gradients correlate with spindle and nuclear size (Kalab et al., 2006), one possibility is that nuclear size predefines the gradient by setting the range of the matrix over which the spindle assembles or by pre-accumulating SAFs according to nuclear size during interphase. Interestingly, in mitosis slow diffusion of former nucleoplasmic components, mediated by a membranous "spindle envelope," results in their prolonged residence within the vicinity of the forming spindle, providing another mechanism whereby nuclear size might impact spindle size (Pawar et al., 2014, Schweizer et al., 2015)

Another parallel between spindle and nuclear scaling involves importin $\alpha$, whose levels impact the sizes of both nuclei and spindles. However, the mechanisms of action differ; importin $\alpha$ affects nuclear size by regulating bulk nuclear import (Levy and Heald, 2010), while in the case of the spindle it binds and inhibits the MT-destabilizing activity of Kif2a (Fig. 1) (Wilbur and Heald, 2013). As already discussed, the importin $\alpha$ cargo lamin B3 (LB3) affects interphase nuclear size. In mitosis, LB3 was observed to form a matrix-like network that scaffolds SAFs in a RanGTP-dependent but not MTdependent manner. Interestingly, spindle assembly was disrupted in Xenopus egg extract depleted of LB3 or upon addition of a LB3 assembly mutant, giving rise to spindles with unfocused poles, asters, or half spindles, due to failure to assemble a spindle matrix and recruit key SAFs such as Eg5 and NuMa (Tsai et al., 2006). Open questions are whether LB3 levels might scale spindle size by defining the size of the matrix-like network (Shi et al., 2014) and whether chromatin organization might contribute to the shaping of spindle molecular gradients.

MT dynamics have been implicated in size scaling of both the spindle and nucleus. Total MT mass and growth velocity driven by XMAP215 levels were reported to define spindle size (Reber et al., 2013), and modulation of MT severing and depolymerization can also impact spindle size (Loughlin et al., 2011, Wilbur and Heald, 2013). Such effects on MT dynamics could also influence rates of nuclear expansion driven by dynein-dependent transport of nucleartargeted membrane, discussed later in this review (Hara and Merten, 2015). As already cited, MT dynamics at the end of mitosis are also relevant to nuclear morphology, as depletion of Dppa2 from Xenopus egg extract gives rise to small, misshapen nuclei (Xue et al., 2013). Therefore, proper nuclear morphology depends on spatio-temporal control of MT network dynamics. Future studies will address whether nuclear size might program spindle size by defining physical assembly dimensions, chromatin organization, and/or SAF concentration gradients. 


\section{Xenopus cell-free extracts to study size regulation of other subcellular structures}

Xenopus egg extracts support assembly of ER networks, and thus provide a useful platform to study ER morphology, dynamics, and size (Dreier and Rapoport, 2000, Voeltz et al., 2006). Cell cycle regulated changes in ER structure have been studied in Xenopus egg extracts, where ER tubules and sheets dominate in interphase and mitosis, respectively. In interphase, ER formation starts with the concentration of membrane at MTOCs by dynein-dependent transport, followed by the outward spreading of ER tubules through association with the plus ends of growing MTs. Although MTs are not required for the formation of an ER network, when present they dictate the spatial organization of the ER. In mitosis, connections between the ER and MTs are reduced (Wang et al., 2013).

As already discussed, the Xenopus system has been used to demonstrate how ER structure impacts nuclear size (Anderson and Hetzer, 2007, Anderson and Hetzer, 2008, Jevtic and Levy, 2015). ER networks formed in egg extract might be used to study ER functions such as protein folding, vesicular transport to the Golgi, and lipid synthesis, all activities with potential links to size scaling of other membrane-bound organelles that are interconnected with the ER. It has also been reported that Golgi and mitochondria can be reassembled in Xenopus egg extract (Lu et al., 2006). It is important to understand the mechanisms that regulate the sizes of the ER and other interconnected organelles, as their sizes and activities often change in response to environmental signals and stress. For example, limited protein folding capacity of the ER plays an important role in the pathogenesis of many diseases, including diabetes mellitus, viral infections, retinitis pigmentosa, and Alzheimer's disease (Lin et al., 2008).

\section{Microfluidic technology and Xenopus cell-free extracts}

Microfluidic technology has great potential to advance our understanding of size scaling of subcellular structures. With microfluidicbased encapsulation, cytoplasmic extract droplets can be generated in microfluidic devices, allowing for exquisite control of droplet size and geometry. In combination with microscopy, this approach enables one to assess the effects of boundary confinement and volume on the size and shape of in vitro assembled structures. The basic device we employ is a T-junction droplet generator with two inlets. An oil-surfactant mixture pumped through one inlet merges with Xenopus egg extract injected through a second inlet, forming extract droplets. The dimensions of the channels at the T-junction and relative flow rates of the two phases determine droplet volume, while dimensions of the droplet collection reservoir dictate droplet shape. Such experiments demonstrated that spindle size is sensitive to cytoplasmic volume and not shape (Fig. $3 \mathrm{C}$ ), recapitulating scaling of spindle size observed during early Xenopus embryogenesis (Good et al., 2013, Hazel et al., 2013). Future applications of these droplet-generating devices include studies of nuclear scaling and ER organization by cytoplasmic volume (Fig. 2E).

Nuclear scaling has been investigated using a related technique involving confinement of Xenopus egg extract and preassembled nuclei in microfluidic channels of defined dimensions. By this approach, nuclear growth was observed to positively correlate with channel dimensions, suggesting that cytoplasmic volume is an important determinant of nuclear size. Above a certain threshold volume of accessible cytoplasm, nuclear size reached a plateau, corresponding to the available space occupied by the MT centrosomal aster localized to, and emanating away from, the nucleus. The volume occupied by this aster was proposed to limit dyneinmediated transport of membrane to the nucleus, thereby limiting nuclear expansion (Hara and Merten, 2015). As continuous microfluidic channels were used in these experiments, how precise modulation of cytoplasmic volume regulates nuclear growth is an open question. It will also be important to determine the relative contributions of the ER network and dynein-MT asters to nuclear size control in this system.

Xenopus egg extract and microfluidic technology have also been employed to study cytoskeletal organization outside the specific context of spindle and nuclear assembly. Confinement of Xenopus extract in spherical geometries with an oil boundary led to the polymerization of actin ring-like structures (Pinot et al., 2012). The actin organization varied with droplet size, exhibiting a linear correlation between droplet diameter and size of the actin ring, indicating actin self-organization scales with droplet size. This resembled symmetry breaking similar to what happens when intracellular actin networks under actomyosin tension are released and only actin flow can be observed (Paluch et al., 2006). Similarly, it was shown that droplet size and shape can have a profound effect on the spatial organization of MT assemblies (Pinot et al., 2009).

Microfluidic technology can be further employed to study spindle and nuclear positioning within the cell. Sea urchin embryos encapsulated within microfluidic chambers of varying shapes always position their nuclei at the center of mass utilizing the MT, rather than actin, cytoskeleton. Dynein-dependent pulling forces on MTs are proposed to mediate this nuclear positioning, with pulling forces being directly proportional to MT length, thus explaining the centering of the nucleus along the longest MTs in the cell (Minc et al., 2011). The scaling of such mechanical forces as a function of confinement might be studied with extract droplets that have a functionalized cortex, mimicking the cellular cortex and allowing for easy manipulation of cytoplasmic volume, composition, and geometry. A minimal system might include chemical modification of the oil/surfactant droplet periphery to resemble a lipid bilayer capable of recruiting dynein (Roth et al., 2014). In summary, microfluidic technology coupled with cell-free extracts has the potential to greatly expand our understanding of not only organelle size scaling, but also how cell size and shape affect self-organization of the cytoskeleton.

\section{Concluding remarks}

The Xenopus in vitro cell-free system has been an invaluable platform in shaping our current understanding of how nuclear and spindle size are regulated. In this review, we discussed how species- and developmental-specific cues as well as cell size, cytoplasmic volume, and DNA amount influence size scaling of both the spindle and nucleus. Common factors that regulate size and function of both the spindle and nucleus include the small GTPase Ran, importin $\alpha$, lamins, TPX2, and MT dynamics. It remains to be elucidated if a causative relationship between nuclear and spindle size exists and whether nuclear size might program spindle size. Emerging technologies, such as microfluidics (Liu and Singh, 2013), advances in microscopy (Zumbusch et al., 2013), and high-throughput imaging (Shachar et al., 2015) greatly 
expand the possibilities for studying organelle size scaling in the Xenopus extract system.

Our improved mechanistic understanding of organelle size regulation will facilitate future studies into the functional significance of nuclear and spindle size during normal development and differentiation. Furthermore, it is now becoming possible to investigate how altered organelle morphology contributes to diverse disease states such as cancer, progeria and other laminopathies, and disorders associated with misfolded proteins (Godinho et al., 2009, Lin et al., 2008, Yazdani et al., 2012, Zwerger et al., 2011). Notably, cancer cells with increased nuclear size generally exhibit perturbed higher order chromatin structure that can contribute to increased mutation frequencies (Schuster-Bockler and Lehner, 2012). There are important open questions about the potential link between altered nuclear size and chromatin organization, the contribution of oncogenes and tumor suppressors to nuclear enlargement, and whether reducing nuclear size in cancer cells might reverse tumorigenic potential. The Xenopus cell-free extract system will continue to be an important tool in answering fundamental questions about the regulation of organelle morphology, answers that promise to provide novel approaches to disease diagnosis, prevention, and treatment.

\section{Acknowledgements}

Research in the Gatlin laboratory is supported by the NIH/NIGMS (R01GM102428), the Pew Scholars Program in the Biomedical Sciences, and the Marine Biological Laboratories Whitman Center. Research in the Levy laboratory is supported by the NIH/NIGMS (R15GM106318 and R01GM113028) and American Cancer Society (RSG-15-035-01-DDC).

\section{References}

AMODEO, A.A., JUKAM, D., STRAIGHT, A.F. and SKOTHEIM, J.M. (2015). Histone titration against the genome sets the DNA-to-cytoplasm threshold for the Xenopus midblastula transition. Proc Natl Acad Sci USA 112: E1086-E1095.

ANDERSON, D.J. and HETZER, M.W. (2007). Nuclear envelope formation by chromatin-mediated reorganization of the endoplasmic reticulum. Nat Cell Biol 9: 1160-1166.

ANDERSON, D.J. and HETZER, M.W. (2008). Reshaping of the endoplasmic reticulum limits the rate for nuclear envelope formation. J Cell Biol 182: 911-924.

BECKER, B.E. and GARD, D.L. (2000). Multiple isoforms of the high molecular weight microtubule associated protein XMAP215 are expressed during development in Xenopus. Cell Motil Cytoskeleton 47: 282-295.

BENAVENTE, R., KROHNE, G. and FRANKE, W.W. (1985). Cell type-specific expression of nuclear lamina proteins during development of Xenopus laevis. Cell 41: 177-190.

BROWN, K.S., BLOWER, M.D., MARESCA, T.J., GRAMMER, T.C., HARLAND R.M. and HEALD, R. (2007). Xenopus tropicalis egg extracts provide insight into scaling of the mitotic spindle. J Cell Biol 176: 765-770.

BURBANK, K.S., MITCHISON, T.J. and FISHER, D.S. (2007). Slide-and-cluster models for spindle assembly. Curr Biol 17: 1373-1383.

CAUDRON, M., BUNT, G., BASTIAENS, P. and KARSENTI, E. (2005). Spatial coordination of spindle assembly by chromosome-mediated signaling gradients. Science 309: 1373-1376.

CHAN, J.Y. (2011). A clinical overview of centrosome amplification in human cancers. Int J Biol Sci 7: 1122-1144.

CHAN, R.C. and FORBES, D.I. (2006). In vitro study of nuclear assembly and nuclear import using Xenopus egg extracts. Methods Mol Biol 322: 289-300.

CHOW, K.H., FACTOR, R.E. and ULLMAN, K.S. (2012). The nuclear envelope environment and its cancer connections. Nat Rev Cancer 12: 196-209.

CLUTE, P. and MASUI, Y. (1995). Regulation of the appearance of division asynchrony and microtubule-dependent chromosome cycles in Xenopus laevis embryos. Dev
Biol 171: 273-285.

COLLART, C., ALLEN, G.E., BRADSHAW, C.R., SMITH, J.C. and ZEGERMAN, P. (2013). Titration of four replication factors is essential for the Xenopus laevis midblastula transition. Science 341: 893-896.

COLLART, C., OWENS, N.D., BHAW-ROSUN, L., COOPER, B., DE DOMENICO, E. PATRUSHEV, I., SESAY, A.K., SMITH, J.N., SMITH, J.C. and GILCHRIST, M.J. (2014). High-resolution analysis of gene activity during the Xenopus mid-blastula transition. Development 141: 1927-1939.

COURTOIS, A., SCHUH, M., ELLENBERG, J. and HIIRAGI, T. (2012). The transition from meiotic to mitotic spindle assembly is gradual during early mammalian development. J Cell Biol 198: 357-370.

DESAI, A., MURRAY, A., MITCHISON, T.J. and WALCZAK, C.E. (1999). The use of Xenopus egg extracts to study mitotic spindle assembly and function in vitro. Methods Cell Biol 61: 385-412.

DINARINA, A., PUGIEUX, C., CORRAL, M.M., LOOSE, M., SPATZ, J., KARSENTI, E. and NEDELEC, F. (2009). Chromatin shapes the mitotic spindle. Cell138:502-513.

DREIER, L. and RAPOPORT, T.A. (2000). In vitro formation of the endoplasmic reticulum occurs independently of microtubules by a controlled fusion reaction. J Cell Biol 148: 883-898.

DUMONT, S. and MITCHISON, T.J. (2009). Force and length in the mitotic spindle. Curr Biol 19: R749-R761.

EDENS, L.J. and LEVY, D.L. (2014a). cPKC regulates interphase nuclear size during Xenopus development. J Cell Biol 206: 473-483.

EDENS, L.J. and LEVY, D.L. (2014b). Size scaling of subcellular organelles and structures in Xenopus laevis and Xenopus tropicalis. In Xenopus Development, (ed. KLOC, M. and KUBIAK, J. Z.). John Wiley \& Sons, Inc., Hoboken, New Jersey, pp.325-345.

EDENS, L.J. and LEVY, D.L. (2016). A cell-free assay using Xenopus laevis embryo extracts to study mechanisms of nuclear size regulation. J. Vis. Exp. doi: $10.3791 / 54173$.

EDENS, L.J., WHITE, K.H., JEVTIC, P., LI, X. and LEVY, D.L. (2013). Nuclear size regulation: from single cells to development and disease. Trends Cell Biol 23: 151-159.

FINGAR, D.C., SALAMA, S., TSOU, C., HARLOW, E. and BLENIS, J. (2002). Mammalian cell size is controlled by mTOR and its downstream targets S6K1 and 4EBP1/elF4E. Genes Dev 16: 1472-1487.

GAETZ, J., GUEROUI, Z., LIBCHABER, A. and KAPOOR, T.M. (2006). Examining how the spatial organization of chromatin signals influences metaphase spindle assembly. Nat Cell Biol 8: 924-932.

GANEM, N.J., GODINHO, S.A. and PELLMAN, D. (2009). A mechanism linking extra centrosomes to chromosomal instability. Nature 460: 278-282.

GANT, T.M., HARRIS, C.A. and WILSON, K.L. (1999). Roles of LAP2 proteins in nuclear assembly and DNA replication: truncated LAP2beta proteins alter lamina assembly, envelope formation, nuclear size, and DNA replication efficiency in Xenopus laevis extracts. J Cell Biol 144: 1083-1096.

GARD, D.L. and KIRSCHNER, M.W. (1987). A microtubule-associated protein from Xenopus eggs that specifically promotes assembly at the plus-end. $\mathrm{J} \mathrm{Cell} \mathrm{Biol}$ 105: 2203-2215.

GATLIN, J.C., MATOV, A., GROEN, A.C., NEEDLEMAN, D.J., MARESCA, T.J., DANUSER, G., MITCHISON, T.J. and SALMON, E.D. (2009). Spindle fusion requires dynein-mediated sliding of oppositely oriented microtubules. Curr Biol 19: $287-296$

GODINHO, S.A., KWON, M. and PELLMAN, D. (2009). Centrosomes and cancer: how cancer cells divide with too many centrosomes. Cancer Metastasis Rev28: 85-98.

GOEHRING, N.W. and HYMAN, A.A. (2012). Organelle growth control through limiting pools of cytoplasmic components. Curr Biol 22: R330-R339.

GOOD, M.C., VAHEY, M.D., SKANDARAJAH, A., FLETCHER, D.A. and HEALD R. (2013). Cytoplasmic Volume Modulates Spindle Size During Embryogenesis. Science (New York, NY) 342: 856-860.

GOSHIMA, G. and SCHOLEY, J.M. (2010). Control of mitotic spindle length. Annu Rev Cell Dev Biol 26: 21-57.

GRUENBAUM, Y., MARGALIT, A., GOLDMAN, R.D., SHUMAKER, D.K. and WILSON K.L. (2005). The nuclear lamina comes of age. Nat Rev Mol Cell Biol 6: 21-31.

HANNAK, E. and HEALD, R. (2006). Investigating mitotic spindle assembly and function in vitro using Xenopus laevis egg extracts. Nat Protoc 1: 2305-2314. 
HARA, Y., IWABUCHI, M., OHSUMI, K. and KIMURA, A. (2013). Intranuclear DNAdensity affects chromosome condensation in metazoans. Mol Biol Cell24:2442-2453.

HARA, Y. and MERTEN, C.A. (2015). Dynein-Based Accumulation of Membranes Regulates Nuclear Expansion in Xenopus laevis Egg Extracts. Dev Cell33:562-575.

HAZEL, J., KRUTKRAMELIS, K., MOONEY, P., TOMSCHIK, M., GEROW, K., OAKEY, J. and GATLIN, J.C. (2013). Changes in Cytoplasmic Volume Are Sufficient to Drive Spindle Scaling. Science (New York, NY) 342: 853-856.

HEALD, R., TOURNEBIZE, R., BLANK, T., SANDALTZOPOULOS, R., BECKER, P., HYMAN, A. and KARSENTI, E. (1996). Self-organization of microtubules into bipolar spindles around artificial chromosomes in Xenopus egg extracts. Nature 382: $420-425$

HELMKE, K.J. and HEALD, R. (2014). TPX2 levels modulate meiotic spindle size and architecture in Xenopus egg extracts. J Cell Biol 206: 385-393.

JENKINS, H., HOLMAN, T., LYON, C., LANE, B., STICK, R. and HUTCHISON, C. (1993). Nuclei that lack a lamina accumulate karyophilic proteins and assemble a nuclear matrix. J Cell Sci 106 (Pt 1): 275-285.

JEVTIC, P., EDENS, L.J., LI, X., NGUYEN, T., CHEN, P. and LEVY, D.L. (2015). Concentration-dependent Effects of Nuclear Lamins on Nuclear Size in Xenopus and Mammalian Cells. J Biol Chem 290: 27557-27571.

JEVTIC, P., EDENS, L.J., VUKOVIC, L.D. and LEVY, D.L. (2014). Sizing and shaping the nucleus: mechanisms and significance. Curr Opin Cell Biol 28C: 16-27.

JEVTIC, P. and LEVY, D.L. (2014). Mechanisms of nuclear size regulation in model systems and cancer. Adv Exp Med Biol 773: 537-569.

JEVTIC, P. and LEVY, D.L. (2015). Nuclear size scaling during Xenopus early development contributes to midblastula transition timing. Curr Biol 25: 45-52.

KALAB, P., PRALLE, A., ISACOFF, E.Y., HEALD, R. and WEIS, K. (2006). Analysis of a RanGTP-regulated gradient in mitotic somatic cells. Nature 440: 697-701.

KALAB, P., WEIS, K. and HEALD, R. (2002). Visualization of a Ran-GTP gradient in interphase and mitotic Xenopus egg extracts. Science 295: 2452-2456.

KHODJAKOV, A., COLE, R.W., OAKLEY, B.R. and RIEDER, C.L. (2000). Centrosomeindependent mitotic spindle formation in vertebrates. Curr Biol 10: 59-67.

KIESERMAN, E.K. and HEALD, R. (2011). Mitotic chromosome size scaling in Xenopus. Cell Cycle 10: 3863-3870

KOZMA, S.C. and THOMAS, G. (2002). Regulation of cell size in growth, development and human disease: PI3K, PKB and S6K. Bioessays 24: 65-71.

LADOUCEUR, A.M., DORN, J.F. and MADDOX, P.S. (2015). Mitotic chromosome length scales in response to both cell and nuclear size. J Cell Biol 209: 645-652.

LEVY, D.L. and HEALD, R. (2010). Nuclear size is regulated by importin alpha and Ntf2 in Xenopus. Cell 143: 288-298.

LEVY, D.L. and HEALD, R. (2012). Mechanisms of intracellular scaling. Annu Rev Cell Dev Biol 28: 113-135.

LIN, J.H., WALTER, P. and YEN, T.S. (2008). Endoplasmic reticulum stress in disease pathogenesis. Annu Rev Pathol 3: 399-425.

LIU, Y. and SINGH, A.K. (2013). Microfluidic platforms for single-cell protein analysis. $J$ Lab Autom 18: 446-454.

LOUGHLIN, R., WILBUR, J.D., MCNALLY, F.J., NEDELEC, F.J. and HEALD, R. (2011). Katanin contributes to interspecies spindle length scaling in Xenopus. Cell 147: 1397-1407.

LU, P., ZHENG, H. and ZHAI, Z. (2006). In vitro reassembly of nuclear envelopes and organelles in Xenopus egg extracts. Cell Res 16: 632-640.

MADRID, A.S. and WEIS, K. (2006). Nuclear transport is becoming crystal clear. Chromosoma 115: 98-109.

MARESCA, T.J. and HEALD, R. (2006). Methods for studying spindle assembly and chromosome condensation in Xenopus egg extracts. Methods $\mathrm{Mol}$ Biol 322: $459-474$

MARSHALL, W. (2002). Size control in dynamic organelles. Trends Cell Biol 12: 414-419.

MARSHALL, W.F. (2012). Organelle size control systems: from cell geometry to organelle-directed medicine. Bioessays 34: 721-724.

MARSHALL, W.F., QIN, H., RODRIGO BRENNI, M. and ROSENBAUM, J.L. (2005). Flagellar length control system: testing a simple model based on intraflagellar transport and turnover. Mol Biol Cell 16: 270-278.

MILUNOVIC-JEVTIC, A., MOONEY, P., SULERUD, T., BISHT, J. and GATLIN, J.C. (2016). Centrosomal clustering contributes to chromosomal instability and cancer.
Curr Opin Biotechnol 40: 113-118.

MINC, N., BURGESS, D. and CHANG, F. (2011). Influence of cell geometry on division-plane positioning. Cell 144: 414-426.

MISTELI, T. and SPECTOR, D.L. (2011). The Nucleus. Cold Spring Harbor Laboratory Press, Cold Spring Harbor, New York.

MITCHISON, T.J., ISHIHARA, K., NGUYEN, P. and WUHR, M. (2015). Size Scaling of Microtubule Assemblies in Early Xenopus Embryos. Cold Spring Harb Perspect Biol 7: a019182.

MIYAMOTO, D.T., PERLMAN, Z.E., BURBANK, K.S., GROEN, A.C. and MITCHISON, T.J. (2004). The kinesin Eg5 drives poleward microtubule flux in Xenopus laevis egg extract spindles. J Cell Biol 167: 813-818.

MURPHY, C.M. and MICHAEL, W.M. (2013). Control of DNA replication by the nucleus/ cytoplasm ratio in Xenopus. J Biol Chem 288: 29382-29393.

MURRAY, A.W. (1991). Cell cycle extracts. Methods Cell Biol 36: 581-605.

NEWPORT, J. and KIRSCHNER, M. (1982a). A major developmental transition in early Xenopus embryos: I. characterization and timing of cellular changes at the midblastula stage. Cell 30: 675-686.

NEWPORT, J. and KIRSCHNER, M. (1982b). A major developmental transition in early Xenopus embryos: II. Control of the onset of transcription. Cel/30: 687-696.

NEWPORT, J.W., WILSON, K.L. and DUNPHY, W.G. (1990). A lamin-independent pathway for nuclear envelope assembly. J Cell Biol 111: 2247-2259.

NIEUWKOOP, P.D. and FABER, J. (1967). Normal Table of Xenopus laevis (Daudin) North-Holland Publishing Company, Amsterdam.

NURSE, P. (1975). Genetic control of cell size at cell division in yeast. Nature 256 547-551.

O'BRIEN, L.L. and WIESE, C. (2006). TPX2 is required for postmitotic nuclear assembly in cell-free Xenopus laevis egg extracts. J Cell Biol 173: 685-694.

PALUCH, E., VAN DER GUCHT, J. and SYKES, C. (2006). Cracking up: symmetry breaking in cellular systems. J Cell Biol 175: 687-692.

PARNAIK, V.K., CHATURVEDI, P. and MURALIKRISHNA, B. (2011). Lamins, Iaminopathies and disease mechanisms: possible role for proteasomal degradation of key regulatory proteins. J Biosci 36: 471-479.

PAWAR, N., DONTH, C. and WEISS, M. (2014). Anisotropic diffusion of macromolecules in the contiguous nucleocytoplasmic fluid during eukaryotic cell division. Curr Biol 24: 1905-1908.

PESHKIN, L., WUHR, M., PEARL, E., HAAS, W., FREEMAN, R.M., JR., GERHART, J.C., KLEIN, A.M., HORB, M., GYGI, S.P. and KIRSCHNER, M.W. (2015). On the Relationship of Protein and mRNA Dynamics in Vertebrate Embryonic Development. Dev Cell 35: 383-394.

PINOT, M., CHESNEL, F., KUBIAK, J.Z., ARNAL, I., NEDELEC, F.J. and GUEROUI, Z. (2009). Effects of confinement on the self-organization of microtubules and motors. Curr Biol 19: 954-960.

PINOT, M., STEINER, V., DEHAPIOT, B., YOO, B.K., CHESNEL, F., BLANCHOIN L., KERVRANN, C. and GUEROUI, Z. (2012). Confinement induces actin flow in a meiotic cytoplasm. Proc Natl Acad Sci USA 109: 11705-11710.

PROKOCIMER, M., DAVIDOVICH, M., NISSIM-RAFINIA, M., WIESEL-MOTIUK N., BAR, D.Z., BARKAN, R., MESHORER, E. and GRUENBAUM, Y. (2009). Nuclear lamins: key regulators of nuclear structure and activities. J Cell Mol Med 13: $1059-1085$.

RAFELSKI, S.M., VIANA, M.P., ZHANG, Y., CHAN, Y.H., THORN, K.S., YAM, P., FUNG, J.C., LI, H., COSTA LDA, F. and MARSHALL, W.F. (2012). Mitochondria network size scaling in budding yeast. Science 338: 822-824

REBER, S.B., BAUMGART, J., WIDLUND, P.O., POZNIAKOVSKY, A., HOWARD, J. HYMAN, A.A. and JULICHER, F. (2013). XMAP215 activity sets spindle length by controlling the total mass of spindle microtubules. Nat Cell Biol 15: 1116-1122.

ROTH, S., LAAN, L. and DOGTEROM, M. (2014). Reconstitution of cortical Dynein function. Methods Enzymol 540: 205-230.

SAUER, G., KORNER, R., HANISCH, A., RIES, A., NIGG, E.A. and SILLJE, H.H. (2005) Proteome analysis of the human mitotic spindle. Mol Cell Proteomics 4: 35-43.

SCHLAITZ, A.L., THOMPSON, J., WONG, C.C., YATES, J.R., 3RD and HEALD, R. (2013). REEP3/4 ensure endoplasmic reticulum clearance from metaphase chromatin and proper nuclear envelope architecture. Dev Cell 26: 315-323.

SCHUBERT, I. and OUD, J.L. (1997). There is an upper limit of chromosome size for normal development of an organism. Cell 88: 515-520. 
SCHUSTER-BOCKLER, B. and LEHNER, B. (2012). Chromatin organization is a major influence on regional mutation rates in human cancer cells. Nature 488: 504-507.

SCHWEIZER, N., PAWAR, N., WEISS, M. and MAIATO, H. (2015). An organelleexclusion envelope assists mitosis and underlies distinct molecular crowding in the spindle region. J Cell Biol 210: 695-704.

SHACHAR, S., VOSS, T.C., PEGORARO, G., SCIASCIA, N. and MISTELI, T. (2015). Identification of Gene Positioning Factors Using High-Throughput Imaging Mapping. Cell 162: 911-923.

SHAULOV, L., GRUBER, R., COHEN, I. and HAREL, A. (2011). A dominant-negative form of POM121 binds chromatin and disrupts the two separate modes of nuclear pore assembly. J Cell Sci 124: 3822-3834.

SHI, C., CHANNELS, W.E., ZHENG, Y. and IGLESIAS, P.A. (2014). A computational model for the formation of lamin-B mitotic spindle envelope and matrix. Interface Focus 4: 20130063.

STEWART, M. (2007). Molecular mechanism of the nuclear protein import cycle. Nat Rev Mol Cell Biol 8: 195-208.

STICK, R. and HAUSEN, P. (1985). Changes in the nuclear lamina composition during early development of Xenopus laevis. Cell 41: 191-200.

TAKEMOTO, A., KAWASHIMA, S.A., LI, J.J., JEFFERY, L., YAMATSUGU, K., ELEMENTO, O. and NURSE, P. (2016). Nuclear envelope expansion is critical for proper chromosomal segregation during a closed mitosis. J Cell Sci. 129: 1250-1259.

THEERTHAGIRI, G., EISENHARDT, N., SCHWARZ, H. and ANTONIN, W. (2010). The nucleoporin Nup188 controls passage of membrane proteins across the nuclear pore complex. J Cell Biol 189: 1129-1142.

TOURNEBIZE, R., POPOV, A., KINOSHITA, K., ASHFORD, A.J., RYBINA, S., POZNIAKOVSKY, A., MAYER, T.U., WALCZAK, C.E., KARSENTI, E. and HYMAN, A.A. (2000). Control of microtubule dynamics by the antagonistic activities of XMAP215 and XKCM1 in Xenopus egg extracts. Nat Cell Biol 2: 13-19.

TSAI, M.Y., WANG, S., HEIDINGER, J.M., SHUMAKER, D.K., ADAM, S.A., GOLDMAN, R.D. and ZHENG, Y. (2006). A mitotic lamin B matrix induced by RanGTP required for spindle assembly. Science 311: 1887-1893.

TSAI, M.Y. and ZHENG, Y. (2005). Aurora A kinase-coated beads function as microtubule-organizing centers and enhance RanGTP-induced spindle assembly. Curr Biol 15: 2156-2163.

VOELTZ, G.K., PRINZ, W.A., SHIBATA, Y., RIST, J.M. and RAPOPORT, T.A. (2006). A class of membrane proteins shaping the tubular endoplasmic reticulum. Cell 124: $573-586$

VUKOVIC, L.D., JEVTIC, P., EDENS, L.J. and LEVY, D.L. (2016a). New Insights into Mechanisms and Functions of Nuclear Size Regulation. Int Rev Cell Mol Biol 322: 1-59.
VUKOVIC, L.D., JEVTIC, P., ZHANG, Z., STOHR, B.A. and LEVY, D.L. (2016b). Nuclear size is sensitive to NTF2 protein levels in a manner dependent on Ran binding. J Cell Sci 129: 1115-1127.

WALCZAK, C.E., VERNOS, I., MITCHISON, T.J., KARSENTI, E. and HEALD, R (1998). A model for the proposed roles of different microtubule-based motor proteins in establishing spindle bipolarity. Curr Biol 8: 903-913.

WALTERS, A.D., BOMMAKANTI, A. and COHEN-FIX, O. (2012). Shaping the nucleus: Factors and forces. J Cell Biochem 113: 2813-2821.

WANG, S., ROMANO, F.B., FIELD, C.M., MITCHISON, T.J. and RAPOPORT, T.A (2013). Multiple mechanisms determine ER network morphology during the cel cycle in Xenopus egg extracts. J Cell Biol. 203: 801-814.

WEST, M., ZUREK, N., HOENGER, A. and VOELTZ, G.K. (2011). A 3D analysis of yeast ER structure reveals how ER domains are organized by membrane curvature. J Cell Biol 193: 333-346.

WILBUR, J.D. and HEALD, R. (2013). Mitotic spindle scaling during Xenopus development by kif2a and importin alpha. eLife 2: e00290.

WILSON, E.B. (1925). The karyoplasmic ratio. In The Cell in Development and Heredity. The Macmillan Company, New York, pp.727-733.

WORMAN, H.J. and COURVALIN, J.C. (2005). Nuclear envelope, nuclear lamina, and inherited disease. Int Rev Cytol 246: 231-279.

WUHR, M., CHEN, Y., DUMONT, S., GROEN, A.C., NEEDLEMAN, D.J., SALIC, A and MITCHISON, T.J. (2008). Evidence for an upper limit to mitotic spindle length. Curr Biol 18: 1256-1261.

WUHR, M., FREEMAN, R.M., JR., PRESLER, M., HORB, M.E., PESHKIN, L., GYGI, S.P. and KIRSCHNER, M.W. (2014). Deep proteomics of the Xenopus laevis egg using an mRNA-derived reference database. Curr Biol 24: 1467-1475.

XUE, J.Z., WOO, E.M., POSTOW, L., CHAIT, B.T. and FUNABIKI, H. (2013). Chromatin-bound Xenopus dppa2 shapes the nucleus by locally inhibiting microtubule assembly. Dev Cell 27: 47-59.

YANAI, I., PESHKIN, L., JORGENSEN, P. and KIRSCHNER, M.W. (2011). Mapping gene expression in two Xenopus species: evolutionary constraints and developmental flexibility. Dev Cell 20: 483-496.

YAZDANI, M., DEOGRACIAS, R., GUY, J., POOT, R.A., BIRD, A. and BARDE, Y.A (2012). Disease modeling using embryonic stem cells: MeCP2 regulates nuclear size and RNA synthesis in neurons. Stem Cells 30: 2128-39.

ZINK, D., FISCHER, A.H. and NICKERSON, J.A. (2004). Nuclear structure in cancer cells. Nat Rev Cancer 4: 677-687.

ZUMBUSCH, A., LANGBEIN, W. and BORRI, P. (2013). Nonlinear vibrational microscopy applied to lipid biology. Prog Lipid Res 52: 615-632.

ZWERGER, M., HO, C.Y. and LAMMERDING, J. (2011). Nuclear mechanics in disease. Annu Rev Biomed Eng 13: 397-428. 


\section{Further Related Reading, published previously in the Int. J. Dev. Biol.}

Control of timing of embryonic M-phase entry and exit is differentially sensitive to CDK1 and PP2A balance Mohammed El Dika, Damian Dudka, Claude Prigent, Jean-Pierre Tassan, Malgorzata Kloc and Jacek Z. Kubiak Int. J. Dev. Biol. (2014) 58: 767-774 http://dx.doi.org/10.1387/ijdb.140101jk

Nuclear reprogramming in zygotes Chanchao Lorthongpanich, Davor Solter and Chin Yan Lim Int. J. Dev. Biol. (2010) 54: 1631-1640 http://dx.doi.org/10.1387/ijdb.103201cl

Faithful reprogramming to pluripotency in mammals - what does nuclear transfer teach us? Julien Maruotti, Alice Jouneau and Jean-Paul Renard Int. J. Dev. Biol. (2010) 54: 1609-1621 http://dx.doi.org/10.1387/ijdb.103195jm

Cyclin B2/cyclin-dependent kinase1 dissociation precedes CDK1 Thr-161 dephosphorylation upon M-phase promoting factor inactivation in Xenopus laevis cell-free extract

Franck Chesnel, Franck Bazile, Aude Pascal and Jacek Z. Kubiak

Int. J. Dev. Biol. (2007) 51: 297-305

http://dx.doi.org/10.1387/ijdb.072292fc

Remodeling of sperm chromatin induced in egg extracts of amphibians $\mathrm{C}$ Katagiri and $\mathrm{K}$ Ohsumi

Int. J. Dev. Biol. (1994) 38: 209-216

http://dx.doi.org/10.1387/ijdb.7981030
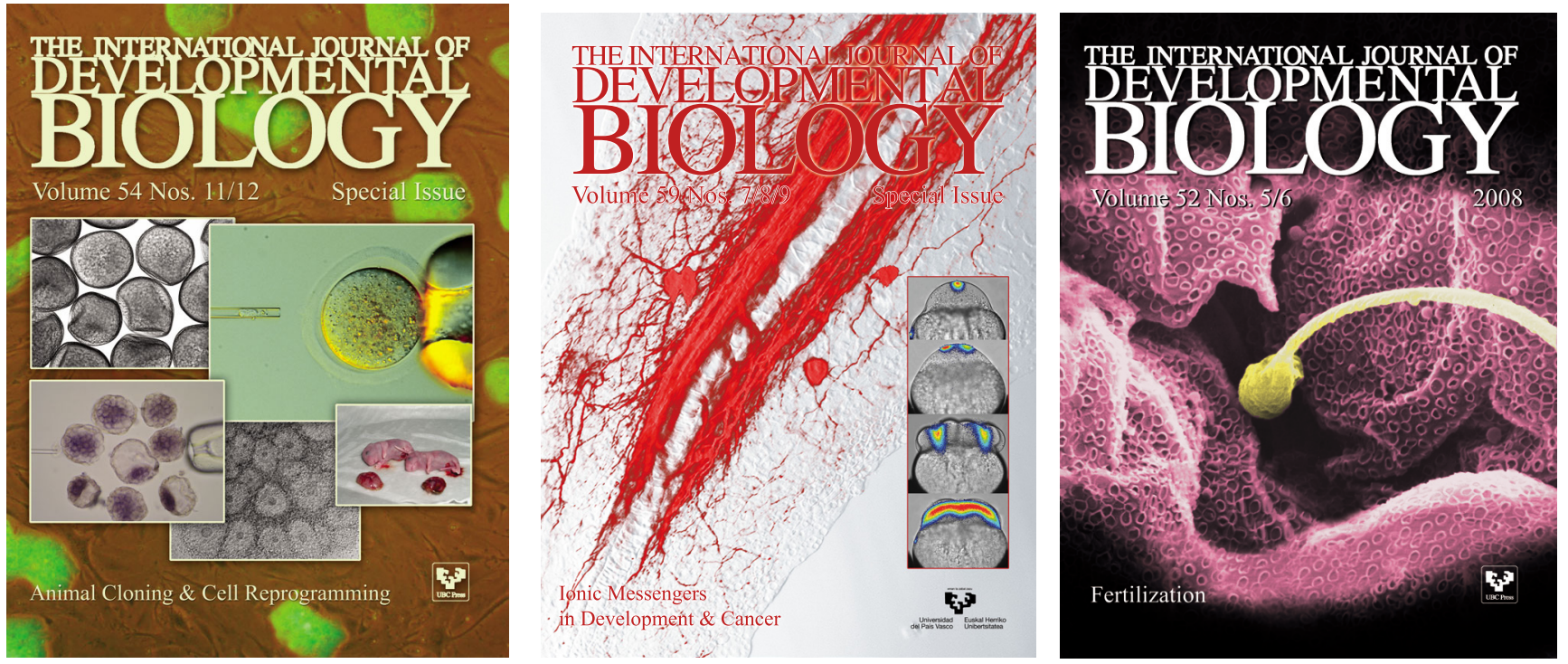